\title{
Intraocular pressure predicts premature coronary atherosclerosis
}

\author{
(iD) Mehmet Kaplan ${ }^{1}$ \\ Did Ozge Ozcan Abacıoglu² \\ (iD) Fethi Yavuz $z^{2}$ \\ (D) Gizem Ilgın Kaplan ${ }^{3}$ \\ (iD) Betül Düzen ${ }^{4}$ \\ (iD) Nurbanu Bursa \\ (iD) Ferhat Zorlu ${ }^{6}$
}

\begin{abstract}
1. Gaziantep University School of Medicine, Department of Cardiology. 27100 , Gaziantep, Turkey. 2. Adana City Training \& Research Hospital, Department of Cardiology, Adana, Turkey 3. Ersin Arslan Training \& Research Hospital, Department of Internal Medicine, Gaziantep, Turkey. 4. Ersin Arslan Training \& Research Hospital, Department of Ophthalmology,, Gaziantep, Turkey. 5. Hacettepe University, Department of Statistics, Ankara, Turkey 6. Adana City Training \& Research Hospital, Department of Ophthalmology, Adana, Turkey
\end{abstract}

\section{SUMMARY}

OBJECTIVE: The aim of this study was to investigate the association between intraocular pressure (IOP) and premature atherosclerotic coronary artery disease (PACAD) by comparing central corneal thicknesses (CCTs) measurements.

METHODS: One hundred-eighty-six subjects were enrolled in this cross-sectional study, 100 in the PACAD group and 86 in the control group. All participants underwent a physical examination and routine biochemical tests. Ophthalmological examinations, including IOP and CCTs measurements, were performed for each subject. Additionally, pulse wave velocity measurements were obtained and recorded.

RESULTS: Participants with PACAD showed significantly higher IOP values than those without atherosclerosis $(p=0.001)$, and there was no statistically significant difference between the groups in terms of CCT ( $p=0.343)$. Also, pulse wave velocity (PWV) values were statistically significantly higher in the PACAD group $(p=0.001)$. High IOP was not significantly associated with metabolic syndrome parameters $(p>0.05)$.

CONCLUSIONS: A relationship was found between PACAD and IOP, but CCTs were not associated with PACAD. The IOP measurement is affected by CCT; therefore, CCT is used to correct IOP values. To our knowledge, this is the first study to report a positive relationship between PACAD and IOP based on CCTs measurements.

KEYWORDS: Intraocular pressure. Atherosclerosis. Glaucoma.

\section{INTRODUCTION}

Glaucoma is a significant cause of irreversible blindness worldwide, and intraocular pressure (IOP) is a modifiable risk factor for glaucoma. IOP is the pressure exerted on the cornea and sclera by the aqueous humor that fills the anterior and posterior chambers, and the mean IOP is $16 \pm 3 \mathrm{~mm} \mathrm{Hg}$. In glaucoma, inflammation has been recognized as a common mechanism'. 
Coronary artery disease (CAD) has become increasingly important due to its prevalence, which has recently risen among younger people ${ }^{2}$. Premature atherosclerotic coronary artery disease (PACAD) has been defined in some studies as CAD occurring in individuals 40 years old or younger, but other studies used a lower age limit of 30 or 50 years ${ }^{3}$. For this study, we used 40 years of age and younger to define PACAD.

Studies have demonstrated that single-vessel involvement is more common in patients with premature CAD than in older patients ${ }^{4}$. In addition, patients with PACAD are more likely to have a family history of hypercholesterolemia, smoking, and $\mathrm{CAD}^{5}$. More careful management of risk factors has been recommended in premature CAD due to its poor prognosis ${ }^{6}$. In the present study, we aimed to determine changes in IOP measures and PWV in patients diagnosed with PACAD.

\section{METHODS}

\section{Study sample}

In this cross-sectional study, we analyzed 186 subjects in two groups: one group of 100 patients with PACAD and a control group of 86 healthy subjects. Approval for the study protocol was granted by the Adana City institutional review board and the study was conducted in accordance with the principles set forth in the Declaration of Helsinki. Written informed consent was obtained from all participants before enrollment. The study exclusion criteria included a history of glaucoma, surgery, use of steroid drugs or diabetic retinopathy, known cardiac disease, renal dysfunction (glomerular filtration rate $<15 \mathrm{~L} / \mathrm{min}$ ), chronic liver disease, rheumatic and hematological diseases, malignancies, active infection, known medication use or chronic conditions that require transfusions.

\section{Data collection}

The study was conducted with two groups, i.e., a PACAD group and a control group. Patients 40 years old or younger with a positive exercise test or ischemia detected by myocardial perfusion scintigraphy and $>50 \%$ lesions in at least one vessel were defined as having PACAD. Obstructive CAD was defined as $\geq 50 \%$ stenosis in any epicardial coronary artery ${ }^{7}$. Individuals with normal coronary arteries as demonstrated by coronary angiography were included in the control group. Coronary lesions were evaluated by two independent cardiologists. All participants underwent a physical examination and biochemical tests. Blood samples were obtained after at least 10 hours of fasting. Hypertension (HT) was defined as systolic blood pressure (SBP) $\geq 140 \mathrm{~mm} \mathrm{Hg}$, diastolic blood pressure (DBP) $\geq 90 \mathrm{~mm} \mathrm{Hg}$, or current use of antihypertensive medication ${ }^{8}$. Diabetes mellitus (DM) was defined as a fasting serum glucose $\geq 126 \mathrm{mg} / \mathrm{dL}$, hemoglobin-A1C $\geq 6.5 \%$, or the use of blood glucose lowering agents ${ }^{9}$. Hypercholesterolemia was defined as low-density lipoprotein (LDL) cholesterol level of $\geq 130 \mathrm{mg} / \mathrm{dL}^{10}$. The components of metabolic syndrome (MS) included a waist circumference of $>102 \mathrm{~cm}$ in men or $>88 \mathrm{~cm}$ in women, triglycerides $\geq 150 \mathrm{mg}$ per $100 \mathrm{ml}$, HDL $<40$ $\mathrm{mg}$ per $100 \mathrm{ml}$ in men or $<50 \mathrm{mg}$ per $100 \mathrm{ml}$ in women (Low-HDL definition), blood pressure $\geq 130 / 85 \mathrm{mmHg}$, and fasting glucose $\geq 100 \mathrm{mg}$ per $100 \mathrm{ml}$. Metabolic syndrome was defined as having at least three of the five components ${ }^{10}$.

Ophthalmological examinations were performed and included the best-corrected visual acuity, refraction, IOP measurement by non-contact and dilated fundus examination. A trained nurse took three consecutive measurements for each eye, and the average IOP of the right eye was used for analysis. Ocular hypertension was defined as an IOP $\geq 21 \mathrm{~mm} \mathrm{Hg}$ in the right eye ${ }^{1}$. Five CCT measurements were obtained from each eye with a Sonomed ultrasound pachymeter (California, USA) and the median reading was taken.

\section{Pulse wave measurement}

After resting, the device was connected to the patient using the Mobil-o-Graph on the right brachial artery traction. PWV was measured with an oscillometric measuring device for at least ten cycles. Three measurements were taken for each patient at 5-minute intervals as recommended. Due to varying heart rates among participants and repeated individual measurements, a correction at a heart rate of 75 beats per minute was automatically calculated and recorded by software for the Augmentation index(AIx@75).

\section{Statistical Analysis}

Statistical analyses were performed using SPSS 23 for Windows (SPSS, USA). The distribution of data was investigated by using the Kolmogorov-Smirnov test. Continuous variables, according to their normal distribution or not, were presented as mean \pm standard deviation or median \pm standard deviation, respectively. Categorical variables were presented as percentages. In the comparison between PACAD and control groups, 
the independent t-test or Mann-Whitney U-test was used for demographic characteristics, biochemical variables, and examinations. In addition, the Spearman correlation coefficient was used in order to analyze the degree of association between parameters. Binomial logistic regression analysis also was performed to evaluate the impact of IOP and PWV measurements on the odds ratio of the event of PACAD. In all analyses, a two-tailed $\mathrm{p}<0.05$ was considered statistically significant.

\section{RESULTS}

A total of 186 participants 40 years old or younger were enrolled in the study, including 100 patients presenting clinical symptoms of stable angina pectoris and 86 age-matched healthy subjects with normal coronary arteries as detected by coronary angiography. The baseline demographic characteristics and laboratory findings of the groups are shown in Table 1. There was no significant difference in CCTs between the study and control groups but the IOP values were significantly greater in the PACAD group ( $\mathrm{p}=0.001)$. Since no meaningful difference was observed between patients and the significance value of the analysis was very close to 0.05 , we considered that the left ventricular ejection

TABLE 1. BASELINE DEMOGRAPHIC CHARACTERISTICS AND BIOCHEMICAL VARIABLES OF THE GROUPS

\begin{tabular}{|c|c|c|c|}
\hline Demographic properties & $\begin{array}{l}\text { PACAD } \\
(n=100)\end{array}$ & $\begin{array}{l}\text { Control } \\
(n=86)\end{array}$ & $\begin{array}{l}\mathrm{p} \\
\text { value }\end{array}$ \\
\hline Age (years, mean) & $34.7 \pm 4.5$ & $34.3 \pm 7.5$ & 0.860 \\
\hline Sex (female, \%) & $48(48 \%)$ & $48(56 \%)$ & 0.290 \\
\hline Hypertension (n, \%) & $20(20 \%)$ & $24(28 \%)$ & 0.206 \\
\hline Diabetes Mellitus (n, \%) & $19(19 \%)$ & $19(22 \%)$ & 0.602 \\
\hline Smoking $(n, \%)$ & $35(35 \%)$ & $16(19 \%)$ & $0.012^{*}$ \\
\hline Hypercholesterolemia $(n, \%)$ & $48(48 \%)$ & $22(25 \%)$ & $0.042^{*}$ \\
\hline Family history for CAD (n, \%) & $36(36 \%)$ & $24(28 \%)$ & 0.386 \\
\hline Metabolic syndrome (n, \%) & $17(17 \%)$ & $14(16 \%)$ & 0.752 \\
\hline \multicolumn{4}{|l|}{ Biochemical variables } \\
\hline Hemoglobin (g/dL) & $12.9 \pm 1.7$ & $12.8 \pm 0.9$ & 0.438 \\
\hline Leukocyte $\left(\times 10^{3} / \mu \mathrm{L}\right)$ & $8.7 \pm 1.7$ & $10.4 \pm 3.3$ & 0.086 \\
\hline Platelet $\left(\times 10^{3} / \mu \mathrm{L}\right)$ & $309 \pm 90$ & $346 \pm 315$ & 0.600 \\
\hline Plasma fasting glucose (mg/dL) & $84 \pm 11$ & $87 \pm 11$ & 0.403 \\
\hline Creatinine (mg/dL) & $0.63 \pm 0.18$ & $0.64 \pm 0.14$ & 0.466 \\
\hline $\mathrm{LDL}-\mathrm{C}(\mathrm{mg} / \mathrm{dL})$ & $109 \pm 30$ & $110 \pm 28$ & 0.727 \\
\hline $\mathrm{HDL}-\mathrm{C}(\mathrm{mg} / \mathrm{dL})$ & $44 \pm 11$ & $44 \pm 8$ & 0.887 \\
\hline $\mathrm{BNP}(\mathrm{pg} / \mathrm{mL})$ & $43 \pm 16$ & $37 \pm 19$ & 0.853 \\
\hline High sensitivity CRP (mg/L) & $1.3 \pm 0.6$ & $1.0 \pm 0.7$ & 0.063 \\
\hline
\end{tabular}

Abbreviations: CA, coronary artery disease; LDL-C, low-density lipoprotein-cholesterol; HDL-C, high-density lipoprotein-cholesterol; BNP, brain natriuretic peptide. ${ }^{*}<0.05$ is significant. fractions did not differ significantly between the groups $(p=0.043)$. However, significantly higher PWV measurements were found in the PACAD group $(p=0.001)$ (Table 2). A high IOP was not significantly associated with MS parameters ( $p>0.05)$. In table 2 , because the IOP and PWV measurements were significant variables, the effects of these measurements on the odds ratio of the event of PACAD were examined with binomial logistic regression analysis. In the analysis, participants with PACAD were used as a reference, and the IOP and PWV measurements were statistically different from the reference. When IOP measurement rises 1 unit, a participant is 2.194 times more likely to belong to the PACAD group than to the control group. Similarly, when the PWV measurement rises 1 unit, a participant is 1.969 times more likely to belong to the PACAD group than to the control group (Table 3). These odds ratios indicate that the IOP and PWV measurements correlate positively with having PACAD.

\section{DISCUSSION}

The relationship between IOP and cardiovascular risk factors suggests that an increased IOP may be associated with cardiovascular disease. To our best knowledge, however, no study in the literature

TABLE 2. OPHTHALMOLOGICAL AND CARDIOLOGIC EXAMINATION FINDINGS OF THE GROUPS

\begin{tabular}{l|l|l|l}
\hline Ophthalmological examination & $\begin{array}{l}\text { PACAD } \\
(\mathrm{n}=100)\end{array}$ & $\begin{array}{l}\text { Control } \\
(\mathrm{n}=86)\end{array}$ & $\begin{array}{l}\mathrm{p} \text {-val- } \\
\text { ue }\end{array}$ \\
\hline Intraocular pressure $(\mathrm{mm} \mathrm{Hg})$ & $14.4 \pm 4.5$ & $13.0 \pm 1.0$ & $0.000^{*}$ \\
\hline Central corneal thickness $(\mu \mathrm{m})$ & $537 \pm 14$ & $535 \pm 19$ & 0.800 \\
\hline Ocular hypertension $(\mathrm{n}, \%)$ & $3(\% 3)$ & $1(\% 1.5)$ & 0.242 \\
\hline Cardiologic examination & & & \\
\hline Ejection Fraction $(\%)$ & $62.6 \pm 3$ & $61.4 \pm 4$ & $0.043^{*}$ \\
\hline Pulse wave velocity $(\mathrm{m} / \mathrm{s})$ & $6 \pm 1.1$ & $5.5 \pm 0.7$ & $0.001^{*}$ \\
\hline
\end{tabular}

${ }^{*} \mathrm{p}<0.05$ is significant.

TABLE 3. RELATIONSHIPS OF INTRAOCULAR PRESSURE AND PULSE WAVE VELOCITY WITH PACAD

\begin{tabular}{l|l|l|l} 
Term & $\begin{array}{l}\text { estimates } \\
\text { with standard } \\
\text { errors }\end{array}$ & OR & $\mathrm{p}$-value \\
\hline Constant $)$ & $-14.439 \pm 2.392$ & - & $<0.001^{*}$ \\
\hline Intraocular pressure $(\mathrm{mm} \mathrm{Hg})$ & $0.786 \pm 0.140$ & 2.194 & $<0.001^{*}$ \\
\hline Pulse wave velocity $(\mathrm{m} / \mathrm{s})$ & $0.677 \pm 0.224$ & 1.969 & $0.002^{*}$ \\
\hline${ }^{*} \mathrm{p}<0.05$ is significant. & \multicolumn{3}{|l}{}
\end{tabular}


examined the relationship between IOP and the risk of cardiovascular disease. Longitudinal studies have shown that the IOP is influenced by diabetes, body mass index (BMI), and BP levels ${ }^{11}$. In the present study, we found elevated IOP in patients with PACAD.

It is well known that the aqueous humor production and outflow facility alters with age $\mathrm{e}^{12},{ }^{13}$. Given the consistent association of IOP with systemic blood pressure (BP) levels and hypertension, it is clear that the influence of age and systemic BP on IOP is complex and cannot be examined in isolation ${ }^{12}$. In one study, individuals who had diabetes were hypertensive with higher BMI and higher SBP and DBP levels and exhibited higher IOP levels ${ }^{14}$. Several cohort studies and population-based cross-sectional studies consistently suggest that blood pressure (BP) and history of DM are positively correlated with IOP ${ }^{15}$. Furthermore, several studies have demonstrated the positive association between IOP and cardiometabolic risk factors or metabolic syndrome ${ }^{16}$.

The mechanism underlying the relationship between BP and IOP is unclear based on the data currently available. However, it may be related to an increase in ocular perfusion pressure which is often associated with increased aqueous humor production $^{17}$. In our study, there was no significant difference between HT and non-HT patients in terms of IOP. Obesity and other metabolic conditions could be considered for the possible shared pathophysiology between CAD and higher IOP. The result of one study showed increased LDL-C, decreased HDL-C, increased triglycerides, and obesity features based on BMI and waist circumference were associated with higher $\mathrm{IOP}^{18}$. Sahinoglu-Keskek et al. ${ }^{19}$ investigated the relative importance of each component of MS and found that elevated IOP was affected by distinct metabolic variables in individual patient groups. However, the subgroups were also examined in detail with respect to the components of metabolic syndrome in our study, and no significant difference was found between the subgroups in terms of IOP and CCT.

Former studies have found that diabetic patients have greater CCTs compared to those without the disease, which may artefactually increase IOP readings depending on the IOP measurements ${ }^{20}$. Among diabetic patients, the CCT was significantly correlated with diabetic duration ${ }^{21}$. However, our study sample included 38 diabetic patients, and the CCT and IOP were not significantly different between DM and non-DM patients. Further studies are warranted to understand the effect of diabetes on the development of glaucoma.

Limited data are available on the link between IOP and CAD. In one study, higher levels of IOP were shown to be significantly associated with the presence of coronary artery calcium (CAC), independent of conventional cardiovascular risk factors. Interestingly, the association between IOP quartiles and the prevalence of detectable coronary calcium artery score was stronger in diabetic subjects, even though the interaction of IOP quartiles and diabetes for calcium artery score was not statistically significant. That study provided more insight into understanding the process of subclinical atherosclerosis in CVD and the relationship with higher IOP as a common pathophysiology ${ }^{18}$. The results of the aforementioned study are interesting and support our findings.

Considerable evidence suggests that systemic and ocular biometric parameters are affected by genetic and environmental factors. Our sample consisted of patients 40 years old or younger presenting with stable angina pectoris diagnosed with severe coronary artery disease, most of them without comorbidities. Higher IOP values found in these patients compared to the control subjects might be related to genetic and environmental factors or individual inflammatory response. Thus, PACAD patients under 40 years of age might be explained by pathophysiology that predominantly involves inflammation rather than a manifest risk factor.

In major studies, pulse pressure and PWV predicted cardiovascular events ${ }^{22}$. Since PWV is the most widely used and validated technique for estimating arterial stiffness, high PWV represents an early sign of arteriosclerosis/atherosclerosis ${ }^{23}$. Consistently, both IOP and PWV were elevated in patients with PACAD in our study. The higher value of IOP and PWV seems to support the inflammatory process.

\section{CONCLUSION}

Although there is a limited number of studies on IOP, we believe that, along with a clinical evaluation, IOP measurement can predict premature atherosclerosis.

Limitations: The cross-sectional design of the current study limits its ability to establish a causal relationship between PACAD and IOP. Further longitudinal studies are needed to clarify the relationship between PACAD and IOP. 


\section{Author's Contribution}

Mehmet Kaplan: all parts. Ozge Ozcan Abacıoglu: conceptualization, formal analysis, methodology, supervision. Fethi Yavuz: data curation, formal analysis, investigation, visualization, writing -original draft.
Gizem Ilgın Kaplan: methodology, software, visualization, writing - original draft. Betül Düzen: data curation, visualization. Nurbanu Bursa: formal analysis, methodology, software, validation. Ferhat Zorlu: data curation.

\section{RESUMO}

OBJETIVO: O objetivo deste estudo é investigar a associação entre a pressão intra-ocular (PIO) e a doença aterosclerótica arterial coronariana prematura (DAACP) compar ando as medidas das espessuras corneanas centrais (ECCS).

MÉTODOs: Cento e oitenta e seis indivíduos foram incluídos no presente estudo transversal, 100 no grupo DAACP e 86 no grupo de controle. Todos os participantes foram submetidos a um exame físico e exames bioquímicos de rotina. Exames oftalmológicos, incluindo PIO e medições das ECCs, foram realizados em cada participante. Além disso, medições de velocidade da onda de pulso foram obtidas e registradas.

RESULTADOS: Os participantes com DAACP apresentaram valores de PIO significativamente maiores do que os daqueles sem aterosclerose ( $p=0,001)$ e não houve diferença estatisticamente significativa entre os grupos em relação $E C C(p=0,343)$. Além disso, os valores das velocidades da onda de pulso (VOP) foram estatisticamente significativamente maiores no grupo DAACP $(p=0,001)$. Um valor elevado de PIO não estava significativamente associado com os parâmetros de síndrome metabólica $(p>0,05)$.

CONCLUSÃo: Encontramos uma relação entre DAACP e PIO, mas as ECCS não estavam associadas com DAACP. A medição da PIO é afetada pela ECC; portanto, a ECC é utilizada para corrigir os valores da PIO. Até onde sabemos, este é o primeiro estudo a relatar uma relação positiva entre DAACP e a PIO com base em medições da ECC.

PALAVRAS-CHAVE: Pressão intraocular. Aterosclerose. Glaucoma.

\section{REFERENCES}

1. Lazaro C, Garcia-Feijoo I, Castillo A, Perea |, Martinez-Casa |M, Garcia-Sanchez J. Impact of intraocular pressure after filtration surgery on visual field progression in primary open-angle glaucoma. Eur J Ophthalmol. 2007;17(3):357-62.

2. Perski A, Olsson G, Landou C, Faire U, Theorell T, Hamsten A. Minimum heart rate and coronary atherosclerosis: independent relations to global severity and rate of progression of angiographic lesions in men with myocardial infarction at a young age. Am Heart J. 1992;123(3):609-16.

3. Yildirim N, Arat N, Doğan MS, Sökmen Y, Ozcan F. Comparison of traditional risk factors, natural history and angiographic findings between coronary heart disease patients with age $<40$ and $>$ or $=40$ years old. Anadolu Kardiyol Derg. 2007;7(2):124-7.

4. Slack J, Evans KA. The increased risk of death from ischaemic heart disease in first degree relatives of 121 men and 96 women with ischaemic heart disease. J Med Genet. 1966;3(4):239-57.

5. Neufeld HN, Goldbourt U. Coronary heart disease: genetic aspects. Circulation. 1983;67(5):943-54.

6. Sharma M, Ganguly NK. Premature coronary artery disease in Indians and its associated risk factors. Vasc Health Risk Manag. 2005;1(3):217-25.

7. Mygind ND, Michelsen MM, Pena A, Frestad D, Dose N, Aziz A, et al. Coronary microvascular function and cardiovascular risk factors in women with angina pectoris and no obstructive coronary artery disease: the iPOWER study. I Am Heart Assoc. 2016;5(3):e003064.

8. Williams B, Mancia G, Spiering W, Rosei EA, Azizi M, Burnier M, et al; ESC Scientific Document Group. 2018 ESC/ESH Guidelines for the management of arterial hypertension. Eur Heart I. 2018;39(33):3021-104.

9. American Diabetes Association. Diagnosis and classification of diabetes mellitus. Diabetes Care. 2010;33(Suppl 1):S62-9.

10. Expert Panel on Detection, Evaluation, and Treatment of High Blood Cholesterol in Adults. Executive summary of the Third Report of The National Cholesterol Education Program (NCEP) expert panel on detection, evaluation, and treatment of high blood cholesterol in adults (adult treatment panel III). JAMA. 2001;285(19):2486-97.

11. Klein BE, Klein R, Knudtson MD. Intraocular pressure and systemic blood pressure: longitudinal perspective: the Beaver Dam Eye Study. Br | Ophthalmol. 2005;89(3):284-7.
12. Wu SY, Nemesure B, Hennis A, Leske MC; Barbados Eye Studies Group. Nine-year changes in intraocular pressure: the Barbados Eye Studies. Arch Ophthalmol. 2006;124(11):1631-6.

13. Gabelt BT, Kaufman PL. Changes in aqueous humor dynamics with age and glaucoma. Prog Retin Eye Res. 2005;24(5):612-37.

14. Chua J, Chee ML, Chin CWL, Tham YC, Tan N, Lim SH, et al. Inter-relationship between ageing, body mass index, diabetes, systemic blood pressure and intraocular pressure in Asians: 6-year longitudinal study. Br J Ophthalmol. 2019;103(2):196-202.

15. Memarzadeh F, Ying-Lai M, Azen SP, Varma R; Los Angeles Latino Eye Study Group. Associations with intraocular pressure in Latinos: the Los Angeles Latino Eye Study. Am J Ophthalmol. 2008;146(1):69-76.

16. Hoehn R, Mirshahi A, Hoffmann EM, Kottler UB, Wild PS, Laubert-Reh $D$, et al. Distribution of intraocular pressure and its association with ocular features and cardiovascular risk factors: the Gutenberg Health Study. Ophthalmology. 2013;120(5):961-8.

17. Poulter NR, Prabhakaran D, Caulfield M. Hypertension. Lancet. 2015;386(9995):801-12.

18. Ye S, Chang Y, Kim CW, Kwon MJ, Choi Y, Ahn J, et al. Intraocular pressure and coronary artery calcification in asymptomatic men and women. $\mathrm{Br} J$ Ophthalmol. 2015;99(7):932-6.

19. Sahinoglu-Keskek N, Keskek SO, Cevher S, Kirim S, Kayiklik A, Ortoglu G, et al. Metabolic syndrome as a risk factor for elevated intraocular pressure. Pak J Med Sci. 2014;30(3):477-82.

20. Tan GS, Wong TY, Fong CW, Aung T; Singapore Malay Eye Study. Diabetes, metabolic abnormalities, and glaucoma. Arch Ophthalmol. 2009;127(10):1354-61.

21. Su DH, Wong TY, Wong WL, Saw SM, Tan DTH, Shen SY, et al; Singapore Malay Eye Study Group. Diabetes, hyperglycemia, and central corneal thickness: the Singapore Malay Eye Study. Ophthalmology. 2008;115(6):964-8.

22. Yıldız M, Gül Ç, Kürüm T. Arterial pulse wave velocity. Türk Kardiyol Dern Arş. 2003;31:504-15.

23. Laurent S, Cockcroft J, Van Bortel L, Boutouyrie P, Giannattasio C, Hayoz D, et al; European Network for Non-invasive Investigation of Large Arteries. Expert consensus document on arterial stiffness: methodological issues and clinical applications. Eur Heart J. 2006;27(21):2588-605. 